\title{
Effect of Dental Finishing Instruments on the Surface Roughness of Composite Resins as Elucidated by Atomic Force Microscopy
}

\author{
Ana Carolina Botta, ${ }^{1}$ Sillas Duarte, Jr., ${ }^{2, \star}$ Pedro Iris Paulin Filho, ${ }^{3}$ and Simoni Maria Gheno ${ }^{3}$ \\ ${ }^{1}$ Department of Restorative Dentistry, São José dos Campos School of Dentistry, São Paulo State University (UNESP), \\ Eng Francisco José Longo, 777, 12245-000, São José dos Campos, São Paulo, Brazil \\ ${ }^{2}$ Department of Comprehensive Care, Case School of Dental Medicine, Case Western Reserve University, 10900 Cleveland, \\ $\mathrm{OH}$ 44106-4905, USA \\ ${ }^{3}$ Department of Materials Engineering, Federal University of São Carlos, São Carlos, São Paulo, Km 235 Rod Washington \\ Luiz, Postal Code 676, 13565-905, Brazil
}

\begin{abstract}
Roughness increases significantly after finishing procedures. The aim of this study was to assess by the atomic force microscope (AFM) the effect of finishing instruments on the surface roughness of composite resins. A nanofiller composite resin (Filtek Supreme, 3M-F) and a microhybrid composite resin (Point 4, Kerr-P) were selected. The finishing procedures were done with a 30 -blade carbide bur (C) and a $30-\mu \mathrm{m}$ finishing diamond bur (D). Standardized specimens were produced and divided into six experimental groups $(n=4)$ according to (1) composite resin, (2) absence of finishing (Mylar matrix-M), and (3) finishing instrument (FM, PM, FC, FD, PC, PD). The mean surface roughness was evaluated by AFM in the contact mode. FM and PM groups were assessed statistically by the Student's T test, and FC, FD, PC, PD groups were submitted to variance analysis (ANOVA), both at 5\% significance. The mean surface roughness values, in nanometers, were FM, 23.63 (b); FC, 283.88 (c); FD, 510.55 (d); PM, 12.52 (a); PC, 343.98 (c); PD, 531.64 (d). Microhybrid composite displayed less roughness than nanofiller composite in the absence of finishing procedures. The 30-blade carbide bur produced less roughness compared to the extra fine diamond bur.
\end{abstract}

Key words: atomic force microscopy, surface roughness, carbide bur, diamond bur, nanofiller composite resin, microhybrid composite resin, finishing techniques

\section{INTRODUCTION}

In dental restoration the use of polymer matrices/composite resins that are mechanically treated with so-called finishing instruments like diamond or carbide burs is a key operation to take care of rough surfaces. Rough surfaces of composite resins contribute to bacterial plaque, debris, and staining accumulation (Heath et al., 1993; Yap et al., 1998, 2000; Wilder et al., 2000; Lopes et al., 2002; Reis et al., 2002, 2003; Nagem Filho et al., 2003). These factors may cause gingival inflammation (Yap et al., 1998, 2000; Wilder et al., 2000; Lopes et al., 2002; Reis et al., 2003; Nagem Filho et al., 2003), secondary caries (Yap et al., 1998, 2000; Lopes et al., 2002; Reis et al., 2003), superficial staining (Heath et al., 1993; Yap et al., 1998, 2000; Wilder et al., 2000; Lopes et al., 2002; Reis et al., 2002, 2003; Nagem Filho et al., 2003; Silikas et al.,

Received January 18, 2008; accepted May 30, 2008

${ }^{\star}$ Corresponding author. E-mail: sillas.duarte@case.edu
2005), and reduction of the restoration gloss (Paravina et al., 2004). Therefore, superficial smoothness is one of the most important properties of a successful restoration (Joniot et al., 2000; Nagem Filho et al., 2003, Yazici et al., 2007).

Many studies (Lutz et al., 1983; Heath et al., 1993; Nagem Filho et al., 2003; Roeder \& Powers, 2004) have shown that polyester matrices provide smooth surfaces. However, polyester matrix insertion and adaptation are not always clinically possible, mainly in areas of difficult access. Thus, finishing dental instruments become indispensable to improving restoration margins, removing overhangs, and producing appropriate contours (Lutz et al., 1983; Jung et al., 1997; Yap et al., 1998; Turssi et al., 2000; Ozgunaltay et al., 2003; Turkun \& Turkun, 2004). Carbide burs (Lutz et al., 1983; Boghosian et al., 1987; Berastegui et al., 1992; Ferracane et al., 1992; Heath et al., 1993; Jung et al., 1997; Joniot et al., 2000; Reis et al., 2002), diamond burs (Lutz et al., 1983; Boghosian et al., 1987; Berastegui et al., 1992; Ferracane et al., 1992; Joniot et al., 2000; Lopes et al., 2002; Reis et al., 2002; Nagem Filho et al., 2003), abrasive impregnated rubber cups and points 
Table 1. Characteristics of the Tested Composite Resins.

\begin{tabular}{|c|c|c|c|c|c|c|}
\hline Material & Manufacturer & Classification & Composition & Average filler size & Shade & Batch \# \\
\hline Filtek Supreme XT (F) & $\begin{array}{l}\text { 3M ESPE, St. Paul, } \\
\text { MN, USA }\end{array}$ & Nanofiller & $\begin{array}{l}\text { Bis-GMA } \\
\text { Bis-EMA } \\
\text { UDMA } \\
\text { TEGDMA }\end{array}$ & $\begin{array}{l}5 \text { to } 20 \mathrm{~nm} \text { with nanoclusters } \\
\text { of } 600 \text { to } 1400 \mathrm{~nm}\end{array}$ & $\mathrm{~A} 2 \mathrm{E}$ & $5 \mathrm{BL}$ \\
\hline Point 4 (P) & Kerr, Orange, CA, USA & Microhybrid & $\begin{array}{l}\text { Bis-GMA } \\
\text { TEGDMA } \\
\text { EBADMA }\end{array}$ & $400 \mathrm{~nm}$ & $\mathrm{~A} 2$ & 424008 \\
\hline
\end{tabular}

(Yap et al., 1998; Joniot et al., 2000; Turssi et al., 2000), abrasive strips, stones (Lutz et al., 1983; Bagheri et al., 2005), polishing pastes (Yannikakis et al., 1998; Turssi et al., 2000), and abrasive discs (Lutz et al., 1983; Berastegui et al., 1992; Heath et al., 1993; Yannikakis et al., 1998; Joniot et al., 2000; Turssi et al., 2000; Lopes et al., 2002; Reis et al., 2002; Nagem Filho et al., 2003; Roeder \& Powers, 2004) have been used for finishing and polishing of composite resin restorations.

The selection of a finishing instrument depends on the nature of the restorative material, localization, and size of a given restoration. Good results have been obtained with flexible discs of aluminum oxide, but their application is limited due to the complexity of the dental anatomy, principally on concave surfaces such as lingual/palatal surfaces of anterior teeth and occlusal surfaces of posterior teeth (Lutz et al., 1983; Jung et al., 1997; Turssi et al., 2000; Nagem Filho et al., 2003). Consequently, the use of carbide burs and/or diamond burs becomes necessary (Jung et al., 1997; Turssi et al., 2000; Nagem Filho et al., 2003; Attar, 2007). However, finishing procedures utilized to remove the excess of restored material may generate an increase in the restoration's superficial roughness (Berastegui et al., 1992; Lopes et al., 2002).

Analysis of the surface roughness of composite resin restorations can be carried out with the atomic force microscope (AFM). AFM topographs provide quantitative threedimensional (3D) information on a sample surface at a nanometric scale. This allows the determination of the surface roughness with high accuracy. Nevertheless, there are few studies that utilize this methodology to analyze surface roughness of restorative materials (Wilder et al., 2000; Silikas et al., 2005, Kakaboura et al., 2007). Therefore, it becomes important to evaluate the influence of the most utilized finishing instruments in clinical practice regarding surface roughness of composite resins. To this end, we have taken advantage of the high spatial resolution of the AFM. The aim of this study was to assess by the AFM the effect of finishing instruments on the surface roughness of composite resins. The null hypothesis tested was that there is no difference in the surface roughness of composite resin restorations submitted to different finishing instruments.

\section{Materials and Methods}

\section{Specimen Preparation}

Nanofiller (Filtek Supreme XT, 3M ESPE, St. Paul, MN) and microhybrid (Point 4, Kerr Corp., Orange, CA) composite resins were used (Table 1). Twenty-four standardized specimens were prepared in stainless steel bipartite matrix with two circular orifices of $11 \mathrm{~mm}$ diameter and $2 \mathrm{~mm}$ thickness. The composite resin was inserted into the matrix using a composite placement instrument followed by the application of an artist's sable brush.

A 10-mm-wide Mylar matrix strip followed by a flat glass slab were used to cover the specimen. A 1-kg stainless steel weight was applied for $30 \mathrm{~s}$ over the specimen, allowing the composite to flow in order to obtain a smoother and standardized surface (Badra et al., 2005). After this period of time, the weight and the glass slab were removed. An 11-mmdiameter polymerization tip was applied directly against the Mylar matrix strip and the specimen light-cured with a halogen light (Demetron Optilux 501, Kerr Corp.). The light output was constantly monitored by a radiometer with an average of $880 \mathrm{~mW} / \mathrm{cm}^{2}$ (build-in LCD digital radiometer Demetron Optilux 501, Kerr Corp.). All the procedures were done according to the manufacturer's instructions.

\section{Finishing Procedures}

Finishing procedures were accomplished using a standardized finishing device, which was designed to guarantee that after specimen removal, the surface would remain flat. The standardized finishing device consisted of a bipartite stainless steel matrix with central height regulation that avoided the finishing instruments contact with the steel matrix surface.

The specimens were randomly assigned into six experimental groups $(n=4)$ according to (1) composite resin; (2) absence of finishing (Mylar matrix-M), and (3) type of finishing instrument (control groups: FM, PM; experimental groups: FC, FD, PC, PD).

During their manufacturing, all the specimens were notched on their reverse side to serve as an orientation aid 
Table 2. Finishing Burs Evaluated.

\begin{tabular}{lllll}
\hline Abbr & Type of instrument & Characteristics & Manufacturer & Batch \\
\hline D & $\begin{array}{l}\text { Diamond bur } \\
\text { \#4219FF }\end{array}$ & $\begin{array}{l}\text { Cylindrical with ogive top, } \\
\text { extra fine granules }(30 \mu \mathrm{m}),\end{array}$ & KG Sorensen, Barueri, SP, Brazil & 040107 \\
& 10-mm active point & & \\
C & Carbide bur \#284 & $\begin{array}{l}\text { Cylindrical with ogive top, } \\
\text { 30 blades, 10.4-mm active point }\end{array}$ & KG Sorensen, Barueri, SP, Brazil & 051201 \\
& & & \\
\hline
\end{tabular}

for the finishing procedures, which were carried out perpendicular to the notch (Wilder et al., 2000). Each finishing instrument was applied over the entire test surface for $15 \mathrm{~s}$ with constant irrigation (Reis et al., 2003; Guler et al., 2005). The instruments used were listed in Table 2 and showed in Figure 1.

After the finishing procedures, the specimens were washed with air-water spray for $5 \mathrm{~s}$ and stored in distilled water at a temperature of $37^{\circ} \mathrm{C} \pm 1$ for $24 \mathrm{~h}$ (Silikas et al., 2005). Next, the specimens were sonicated in deionized water (Habelitz et al., 2001) for 30 min to remove any debris deposited on the surface.

\section{AFM Roughness Evaluation}

The mean surface roughness was assessed with contact mode AFM (Nanoscope IIIa, Digital Instruments, Santa Barbara, CA) in air, equipped with an AS-130 (J) scanner. The scanning of the specimen's surface was done using a $\mathrm{Si}_{3} \mathrm{~N}_{4}$ (NP model) pyramidal tip of $40-\mathrm{nm}$ average nominal radii (Veeco Nanofabrication Center, Veeco Probes, Camarillo, CA), with frequency of $1 \mathrm{~Hz}$, measurement in nanometer $(\mathrm{nm})$, and nominal spring constant of $0.58 \mathrm{~N} / \mathrm{m}$.

Two areas (Wilder et al., 2000) were randomly selected and scanned in the same direction as the finishing procedures. Images of $20 \mu \mathrm{m} \times 20 \mu \mathrm{m}$ of each selected area (Habelitz et al., 2001) with resolution from $512 \times 512$ pixels were obtained and the mean roughness $\left(R_{a}\right)$ calculated using the following equation:

$$
R_{a}=\frac{1}{L_{x} L_{y}} \int_{0}^{L_{y}} \int_{0}^{L_{x}}|f(x, y)| d x d y,
$$

where $f(x, y)$ is the surface relative to the center plane, and $L_{x}$ and $L_{y}$ are the dimensions of the surface (Silikas et al., 1999). The $R_{a}$ analysis was done by Nanoscope IIIa software version 4.22 R2 (Digital Instruments), and the maximum vertical range obtained was $4.7 \mu \mathrm{m}$.

\section{Statistical Analysis}

FM and PM groups were statistically assessed by the Student's T test, at a $5 \%$ level of significance. FC, FD, PC, and PD groups were submitted to variance analysis at 5\% level of significance. To check if there was homogeneity variance

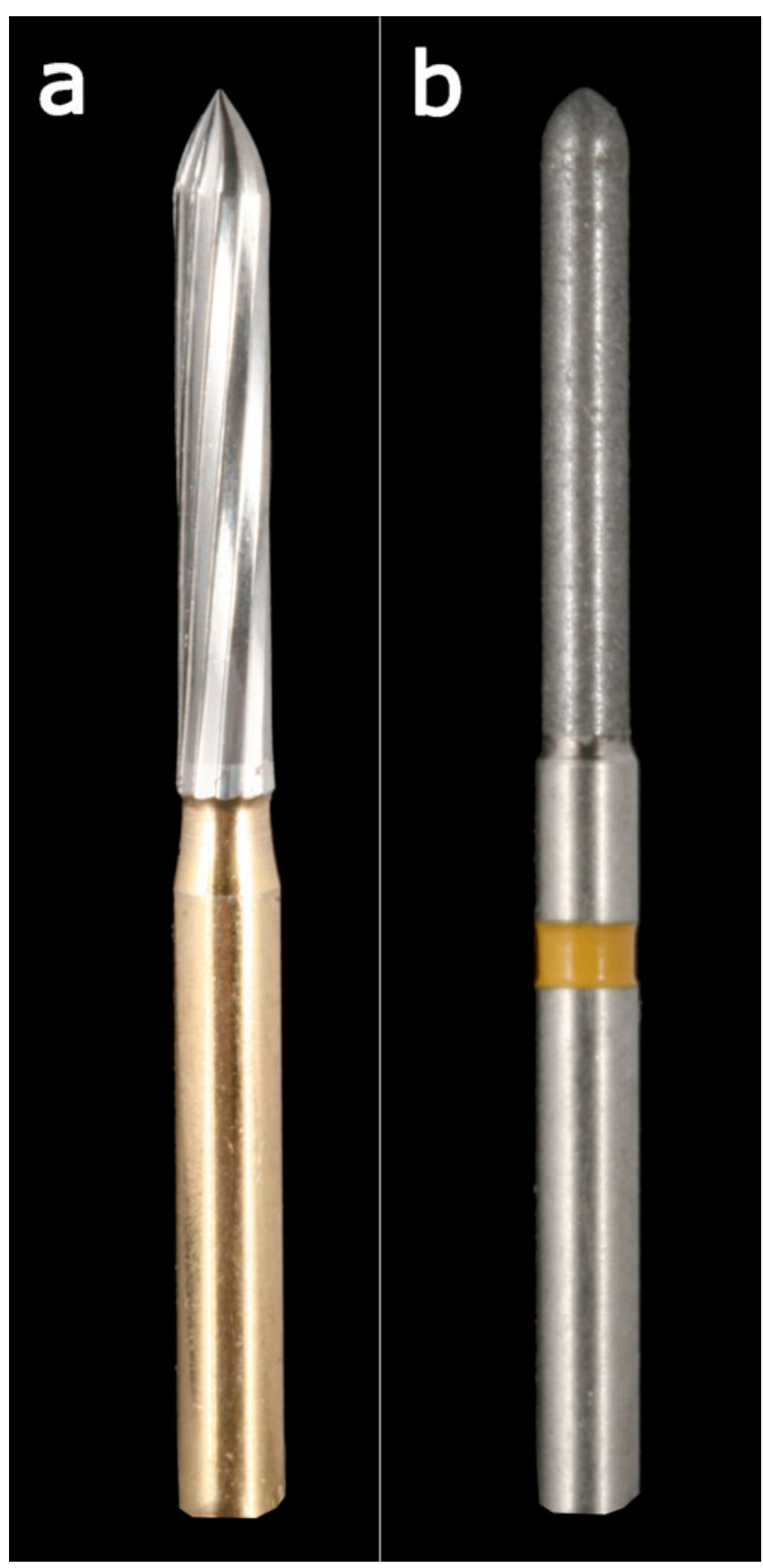

Figure 1. Dental finishing instruments: (a) 30-blade carbide bur and (b) $30-\mu \mathrm{m}$ finishing diamond bur. 
Table 3. Mean Roughness $\left(R_{a}\right)$ in $\mathrm{nm}$ and Standard Deviation of the Experimental Groups.

\begin{tabular}{lcc}
\hline Groups & \multicolumn{1}{c}{$R_{a}$} & $\begin{array}{c}\text { Standard } \\
\text { deviation }\end{array}$ \\
\hline FM & $23.63^{\mathrm{b}}$ & 3.00 \\
FC & $283.88^{\mathrm{c}}$ & 53.70 \\
FD & $510.55^{\mathrm{d}}$ & 66.35 \\
PM & $12.52^{\mathrm{a}}$ & 3.19 \\
PC & $343.98^{\mathrm{c}}$ & 127.03 \\
PD & $531.64^{\mathrm{d}}$ & 57.38 \\
\hline
\end{tabular}

and normality in the experimental errors, the Levene's Test and the Shapiro-Wilk Test were performed.

\section{RESULTS}

Table 3 displays the mean surface roughness value $\left(R_{a}\right)$ in nm and the standard deviation of the experimental groups.

Because the surface roughness significantly increased after the finishing procedures (more than 10-fold over the mean), two independent statistical analyses were carried out. In the absence of finishing, the mean roughness of the Filtek Supreme XT (3M ESPE) was significantly higher than that of Point 4 (Kerr Corp.) $(p=0.002)$ (Fig. 2).

The Levene $(p=0.304)$ and Shapiro-Wilk $(p=0.746)$ tests, respectively, proved the variances homogeneity and the normality of experimental errors for application of variance analysis $(p>0.05)$. A significant effect of finishing instruments on the surface roughness of the studied composites $(p<0.001)$ was observed. The mean roughness values were smaller in the groups that utilized the carbide bur as a finishing instrument (FC and PC), in comparison to groups with diamond bur (FD and PD) (Fig. 3). How-

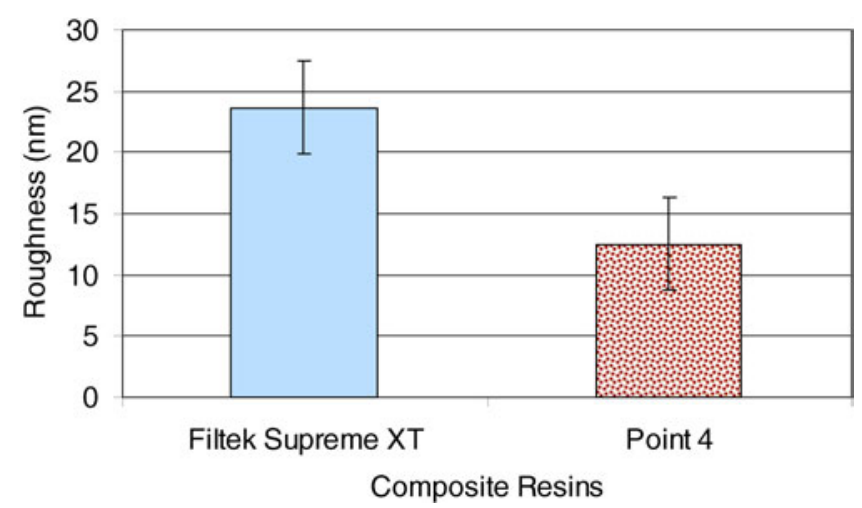

Figure 2. Mean surface roughness $\left(R_{a}\right)$ in $\mathrm{nm}$ according to the composite resin in absence of finishing (controls). The vertical line represents a $95 \%$ confidence interval.

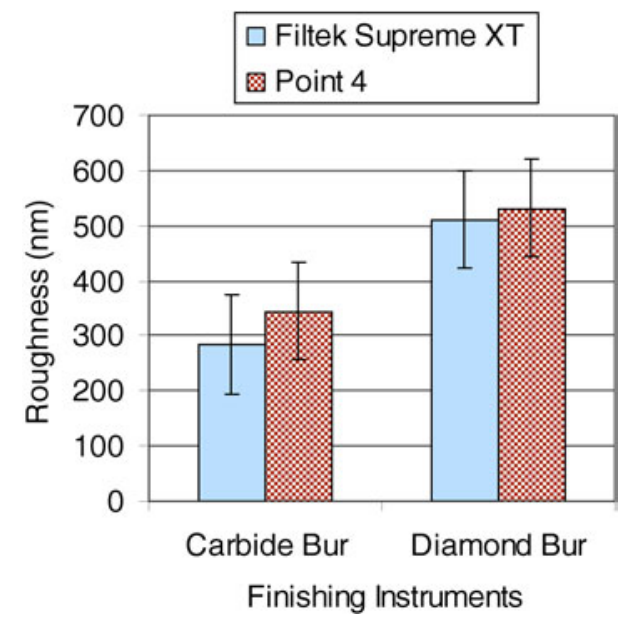

Figure 3. Mean surface roughness $\left(R_{a}\right)$ in $\mathrm{nm}$ according to the composite resin and the finishing instrument. The vertical line represents a $95 \%$ confidence interval.

ever, there was no significant statistical difference between both composite resins regarding surface roughness after utilizing the instruments.

Figures 4-6 correspond to superficial images of the experimental groups obtained via the contact mode of the AFM.

\section{Discussion}

This study shows that the roughness of a restoration not only is directly related to the restorative material, but also to the finishing and polishing instruments (Nagem Filho et al., 2003). The null hypothesis was rejected once we found difference in the surface roughness of composite resin after finishing procedures were made. Finishing procedures of composite resin restorations may be achieved with various instruments. Clinically, the most used finishing instruments are carbide burs and diamond burs (Roeder \& Powers, 2004). Finishing diamond burs vary according to abrasive granulation, distribution, and shape (Lutz et al., 1983). The greater the abrasive granulation, the rougher the surface obtained (Nagem Filho et al., 2003). To be an effective diamond finishing instrument, the abrasives must be harder than the filler of the restorative material (Reis et al., 2002, 2003). Carbide finishing burs may vary according to the number of blades (Berastegui et al., 1992); the higher the number of blades, a smoother and more even surface is produced. The choice of the instrument may depend on the composite resin used. For hybrid resins, the use of carbide burs is recommended and for microfilled resins, the diamond bur is the best finishing instrument (Lutz et al., 1983; Boghosian et al., 1987). Different finishing instruments may be used successively to produce a smoother surface (Jung et al., 1997). 


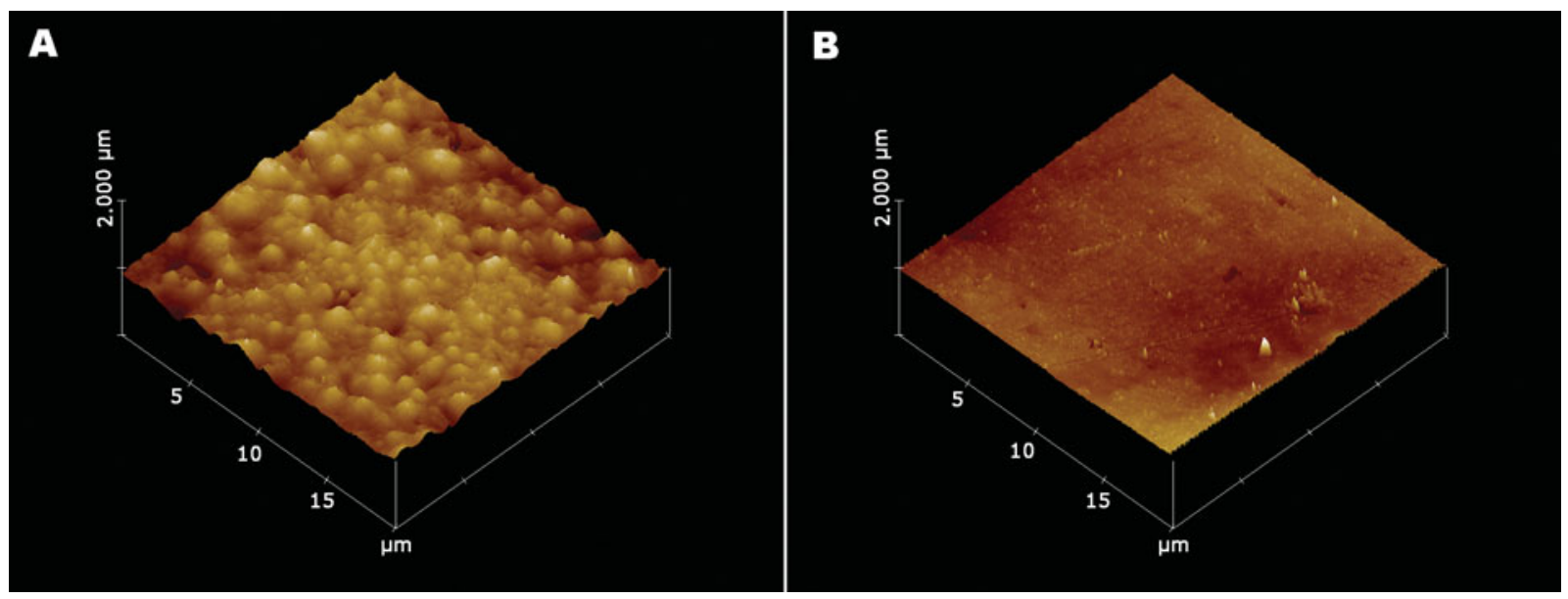

Figure 4. AFM image acquired in the contact mode of the composite resin associated with Mylar matrix $(20 \mu \mathrm{m} \times 20$ $\mu \mathrm{m}$ ): (A) nanofiller composite resin Filtek Supreme XT and (B) mycrohybrid composite resin Point 4.
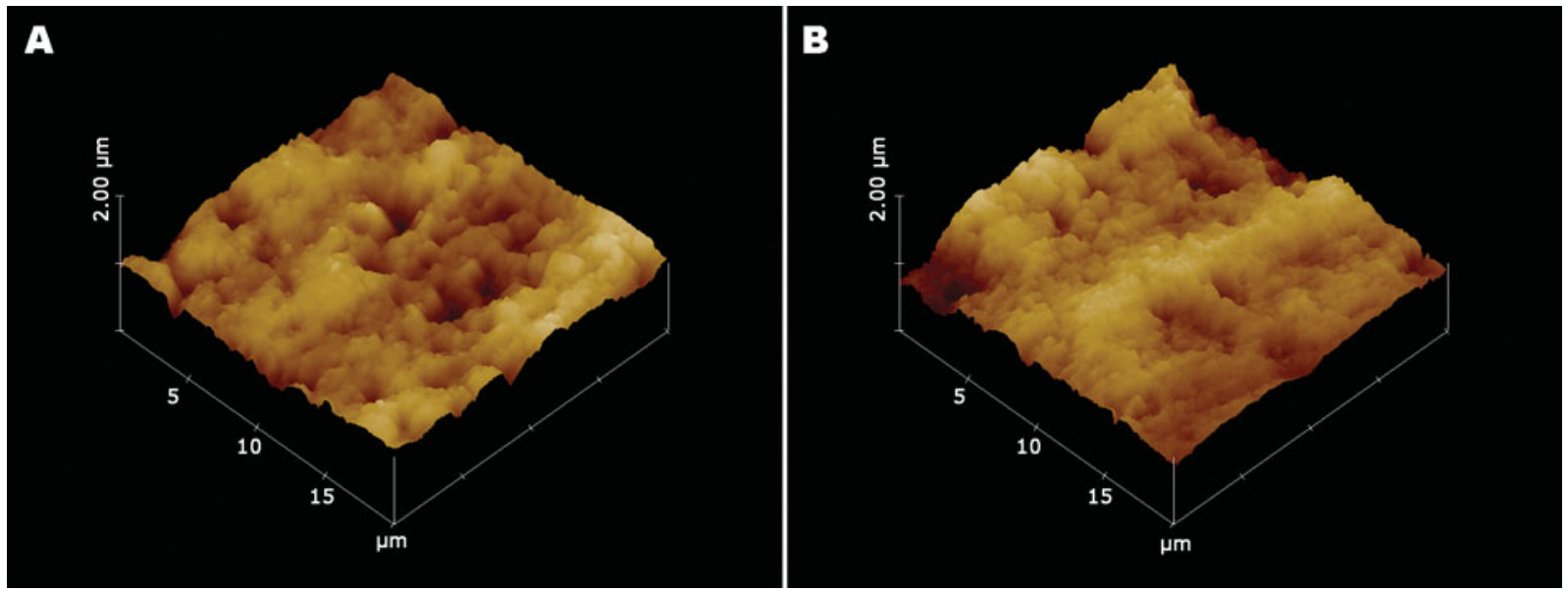

Figure 5. AFM image acquired in the contact mode of the composite resin finished with 30-blade finishing carbide bur $(20 \mu \mathrm{m} \times 20 \mu \mathrm{m}):(A)$ nanofiller composite resin Filtek Supreme XT and (B) mycrohybrid composite resin Point 4.
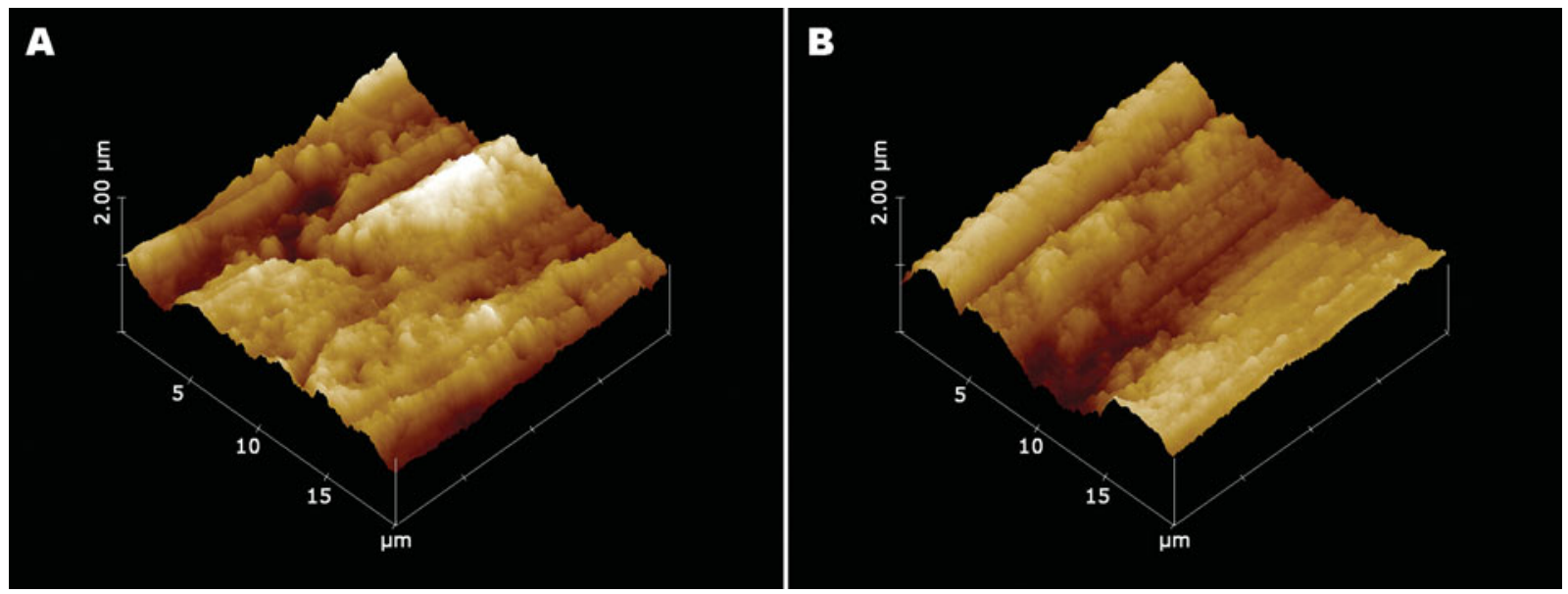

Figure 6. AFM image acquired in the contact mode of the composite resin finished with $30-\mu \mathrm{m}$ finishing diamond bur $(20 \mu \mathrm{m} \times 20 \mu \mathrm{m})$ : (A) nanofiller composite resin Filtek Supreme XT and (B) mycrohybrid composite resin Point 4. 
The surface roughness of the tested composites increased significantly after applying dental finishing instruments (Uctasly et al., 2007). No difference between Filtek Supreme XT (3M ESPE) and Point 4 (Kerr Corp.) was found after the finishing procedures. However, a significant difference was observed in the roughness values between carbide and diamond finishing burs. Carbide bur produced a lower surface roughness independent of the composite resin (Fig. 5A,B) (Turssi et al., 2005). Diamond bur offered a higher cutting effectiveness but resulted in a rougher surface than that produced by the carbide bur (Fig. 6A,B) (Berastegui et al., 1992; Ferracane et al., 1992; Jung et al., 1997; Reis et al., 2002, 2003; Turssi et al., 2005).

In the present study, the control groups displayed the lowest mean roughness. Nevertheless, there was significant statistical difference between the tested composite resins in the absence of finishing. The microhybrid resin (Point 4Kerr Corp.) showed lower roughness than the nanofiller resin (Fig. 4A,B). This may be explained by the consistency of the Point 4 (Kerr Corp.) filler size $(400 \mathrm{~nm})$. Filtek Supreme XT (3M ESPE) has filler sizes ranging from 5 to $20 \mathrm{~nm}$. These nanofillers are much smaller than the ones in Point 4 (Kerr Corp.). However, clusters of 600 to $1400 \mathrm{~nm}$, which are present in Filtek Supreme XT (3M ESPE), might cause an increase in the surface roughness. Silikas et al. (2005) obtained similar results when comparing the surface roughness of this nanofiller resin with a 200-nm filler size microhybrid composite. Thus, shape (Paravina et al., 2004; Heintze et al., 2006), size (Van Dijken et al., 1980; Turssi et al., 2000; Reis et al., 2002; Nagem Filho et al., 2003; Paravina et al., 2004; Turkun \& Turkun, 2004; Heintze et al., 2006), quantity, and distribution of the filler in the composite (Van Dijken et al., 1980; Turssi et al., 2000; Reis et al., 2002; Nagem Filho et al., 2003; Turkun \& Turkun, 2004; Heintze et al., 2006) play an important role in the surface roughness. A smoother surface may be obtained by the arrangement of fillers within the resin matrix or by higher filler content composites (Reis et al., 2002; Nagem Filho et al., 2003; Turkun \& Turkun, 2004).

Despite the higher surface smoothness obtained with the polyester matrix (Chung, 1994; Yap et al., 1998; Ozgunaltay et al., 2003; Paravina et al., 2004; Turkun \& Turkun, 2004), a degree of roughness remained (Yap et al., 1998). When using the polyester matrix, Point 4 (Kerr Corp.) revealed a mean roughness of $12.52 \mathrm{~nm}$ and Filtek Supreme XT (3M ESPE) of $23.63 \mathrm{~nm}$. The restorative surfaces were not free of imperfections due to the nature of the resin matrix (Yap et al., 1998) and possible irregularities in the polyester matrix itself (Turkun \& Turkun, 2004).

The AFM tip apex geometry plays an important role in surface roughness measurements. AFM tip apex can change during measurements due to wear or during storage due oxidation (Wang \& Chen, 2007). Consequently, before a given experiment, quantitative evaluation of the AFM tip apex geometry is imperative. The readings are mainly influenced by the radius of the tip, the pressure of the tip on the surface, and the hardness of the material (Wennerberg et al.,
1996). The larger the AFM tip radius, the smaller the mean surface roughness value and the image resolution. Therefore, the AFM tip should be small enough to detect the smallest roughness features of the specimen.

High-resolution AFM images allow an accurate determination of the surface roughness. In dentistry, AFM permits the exclusion of the specimen defects that may interfere with the data analysis, such as cracks, fissures, and porosity on the restoration surface (Yannikakis et al., 1998; Patel et al., 2004). Furthermore, AFM has the following key features: it can be used under ambient conditions, provides 3D nanometric resolution (Kakaboura et al., 2007), presents high precision and sensitivity (Green et al., 2003; Miles et al., 2003; Seitavuopio et al., 2003), and has no need of fixation and covering during specimen preparation (Miles et al., 2003). Therefore, AFM is an appropriate instrument to analyze surface roughness of composite resins.

\section{CONCLUSIONS}

We conclude that surface roughness significantly increases after finishing. Carbide burs resulted in lower surface roughness compared to diamond burs, independent of the composite resin tested. There was no statistically significant difference between the composite resins regarding surface roughness after the use of finishing instruments. In the absence of finishing, the microhybrid resin (Point 4, Kerr Corp.) presented lower roughness than did the nanofiller resin (Filtek Supreme XT, 3M ESPE). This study has shown that the choice of finishing instrument is highly significant in the ultimate smoothness of composite resin restorations. The smallest influence on the surface roughness of composite resins after finishing has been observed for carbide burs.

\section{ACKNOWLEDGMENTS}

São Paulo State University (UNESP), Federal University of São Carlos, and Case Western Reserve University are the institutions where the research was performed. The authors would like to thank CAPES (grant \# 33004030008M8), the Department of Materials Engineering of the Federal University of São Carlos, and Mário Sérgio Fantini and Cláudio Tita for their assistance. Dr. Bernard Tandler provided editorial assistance.

\section{RefERENCES}

Attar, N. (2007). The effect of finishing and polishing procedures on the surface roughness of composite resin materials. J Contemp Dent Pract 8, 27-35.

Badra, V.V., Faraoni, J.J., Ramos, R.P. \& Palma-Dibb, R.G. (2005). Influence of different beverages on the microhardness and surface roughness of resin composites. Oper Dent 30, 213-219. 
Bagheri, R., Burrow, M.F. \& Tyas, M. (2005). Influence of food-simulating solutions and surface finish on susceptibility to staining of aesthetic restorative materials. J Dent 33, 389-398.

Berastegui, E., Canalda, C., Brau, E. \& Miguel, C. (1992). Surface roughness of finished composite resins. J Prosthet Dent 68, 742-749.

Boghosian, A.A., Randolph, R.G. \& Jekkals, V.J. (1987). Rotatory instrument finishing of microfilled and small-particle hybrid composite resins. J Am Dent Assoc 115, 299-301.

Chung, K. (1994). Effects of finishing and polishing procedures on the surface texture of resin composites. Dent Mater 10, 325-330.

Ferracane, J.L., Condon, J.R. \& Mitchem, J.C. (1992). Evaluation of subsurface defects created during the finishing of composites. J Dent Res 71, 1628-1632.

Green, J.B.D., Idowu, A. \& Chan, S.S.F. (2003). Modified tips: Molecules to cells. Materials Today 6, 22-29.

Guler, A.U., Kurt, S. \& Kulunk, T. (2005). Effects of various finishing procedures on the staining of provisional restorative materials. J Prosthet Dent 93, 453-458.

Habelitz, S., Marshall, S.J., Marshall, G.W., Jr. \& Balooch, M. (2001). Mechanical properties of human dental enamel on the nanometre scale. Arch Oral Biol 46, 173-183.

Heath, J.R., Jordan, J.H. \& Watts, D.C. (1993). The effect of time of trimming on the surface finish of anterior composite resins. J Oral Rehabil 20, 45-52.

Heintze, S.D., Forjanic, M. \& Rousson, V. (2006). Surface roughness and gloss of dental materials as function of force and polishing time in vitro. Dent Mater 22, 146-165.

Joniot, S.B., Grégoire, G.L., Auther, A.M. \& Roques, Y.M. (2000). Three-dimensional optical profilometry analysis of surface states obtained after finishing sequences for three composite resins. Oper Dent 25, 311-315.

Jung, M., Baumstieger, M. \& Klimek, J. (1997). Effectiveness of diamond-impregnated felt wheels for polishing a hybrid composite. Clin Oral Invest 1, 71-76.

Kakaboura, A., Fragouli, M., Rahiots, C. \& Silikas, N. (2007). Evaluation of surface characteristics of dental composites using profilometry, scanning electron, atomic force microscopy and gloss-meter. J Mater Sci Mater Med 18, 155-163.

Lopes, G.C., Franke, M.F. \& MAia, H.P. (2002). Effect of finishing time and techniques on marginal sealing ability of two composite restorative materials. J Prosthet Dent 88, 32-36.

Lutz, F., Setcos, J.C. \& Phillips, R.W. (1983). New finishing instruments for composite resins. J Am Dent Assoc 107, 575-580.

Miles, M., Antognozzi, M., Haschke, H., Hobbs, J., Humphris, A. \& McMaster, T. (2003). Tour de force microscopy. Materials Today 6, 30-37.

Nagem Filho, H., D’azevedo, M.T.F.S., Nagem, H.D. \& MarsolA, F.P. (2003). Surface roughness of composite resins after finishing and polishing. Braz Dent J 14, 37-41.

Ozgunaltay, G., Yazigi, A.R. \& Gorucu, J. (2003). Effect of finishing and polishing procedures on the surface roughness of new tooth-coloured restoratives. J Oral Rehabil 30, 218-224.

Paravina, R.D., Roeder, L., Lu, H., Vogel, K. \& Powers, J.M. (2004). Effect of finishing and polishing procedures on surface roughness, gloss and color of resin composites. Am J Dent 17, 262-266.

Patel, S.B., Gordan, V.V., Barrett, A.A. \& Shen, C. (2004). The effect of surface finishing and storage solutions on the color stability of resin-based composites. J Am Dent Assoc 135, 587-594.
Reis, A.F., Giannini, M., Lovadino, J.R. \& Ambrosano, G.M. (2003). Effects of various finishing systems on the surface roughness and staining susceptibility of packable composite resins. Dent Mater 19, 12-18.

Reis, A.F., Giannini, M., Lovadino, J.R. \& Dias, C.T.S. (2002). The effect of six polishing systems on the surface roughness of two packable resin-based composites. Am J Dent 15, 193-197.

Roeder, L.B. \& Powers, J.M. (2004). Surface roughness of resin composite prepared by single-use and multi-use diamonds. Am J Dent 17, 109-112.

Seitavuopio, P., Rantanen, J. \& Yliruusi, J. (2003). Tablet surface characterization by various imaging techniques. Int J Pharm 254, 281-286.

Silikas, N., Kavvadia, K., Eliades, G. \& Watts, D. (2005). Surface characterization of modern resin composites: A multitechnique approach. Am J Dent 18, 95-100.

Silikas, N., Watts, D.C., England, K.E.R. \& JandT, K.D. (1999). Surface fine structure of treated dentine investigated with tapping mode atomic force microscopy (TMAFM). J Dent 27, 137-144.

Turkun, L.S. \& Turkun, M. (2004). The effect of one-step polishing system on the surface roughness of three esthetic resin composite materials. Oper Dent 29, 203-211.

Turssi, C.P., Ferracane, J.L. \& Serra, M. (2005). Abrasive wear of resin composites as related to finishing and polishing procedures. Dent Mater 21, 641-648.

Turssi, C.A., SAad, J.R.C., Duarte, S.L.L., Jr. \& Rodrigues, A.L., JR. (2000). Composite surfaces alter finishing and polishing techniques. Am J Dent 13, 136-138.

Uctasly, M.B., Arisu, H.D., OMürlü, H., EligüZeloglu, E., Ozcan, S. \& Ergun, G. (2007). The effect of different finishing and polishing systems on the surface roughness of different composite restorative materials. J Contemp Dent Pract 8, 89-96.

Van Dijken, J.W.V., Meurman, J.H. \& Jarvinen, J. (1980). Effect of finishing procedures on surface textures of some resin restoratives. Acta Odontol Scand 38, 293-301.

Wang, Y. \& Chen, X. (2007). Carbon nanotubes: A promising standard for quantitative evaluation of AFM tip apex geometry. Ultramicroscopy 107, 293-298.

Wennerberg, A., Ohlsson, R., Rosén, B.G. \& Andersson, B. (1996). Characterizing three-dimensional topography of engineering and biomaterial surfaces by confocal laser scanning and stylus techniques. Med Eng Phys 18, 548-556.

Wilder, A.D., Jr., Swift, E.J., JR., MaY, K.N., Jr., Thompson, J.Y. \& McDougal, R.A. (2000). Effect of finishing technique on the microleakage and surface texture of resin-modified glass ionomer restorative materials. J Dent 28, 367-373.

Yannikakis, A.S., Zissis, A.J., Polyzois, G.L. \& Caroni, C. (1998). Color stability of provisional resin restorative materials. J Prosthet Dent 80, 33-539.

YAP, A.U., Low, J.S. \& ONG, L.F. (2000). Effect of food-simulating liquids on surface characteristics of composite and polyacidmodified composite restoratives. Oper Dent 25, 170-176.

YAP, A.U.J., SAU, C.W. \& LYE, K.W. (1998). Effects of finishing/ polishing time on surface characteristics of tooth-coloured restoratives. J Oral Rehabil 25, 456-461.

YAZICI, A.R., Müftü, A. \& Kugel, G. (2007). Three-dimensional surface profile analysis of different types of flowable restorative resins following different finishing protocols. J Contemp Dent Pract 8, 9-17. 